\title{
Structural Behavior of Lightweight Composite Slab System
}

\author{
Nur Adidah Sutiman ${ }^{1}$, Masni A. Majid ${ }^{1 *}$, Zainorizuan Mohd Jaini ${ }^{1}$, Aina \\ Syafawati Roslan ${ }^{1}$
}

${ }^{1}$ Jamilus Research Centre, Faculty of Civil Engineering and Built Environment, Universiti Tun Hussein Onn Malaysia, Parit Raja, 86400, MALAYSIA

*Corresponding Author

DOI: https://doi.org/10.30880/ijie.2021.13.03.007

Received 22 September 2020; Accepted 09 March 2021; Available online 01 June 2021

\begin{abstract}
This study investigate the structural behavior of lightweight composite slab system that consist of profiled steel sheet (PSS) attached to dry board (DB) using mechanical screws and with or without infill materials. A total four full-scale panel specimen were tested under four-point bending when subjected under static loading. Result of the four-point test shows that increasing the thickness of profiles steel sheet gives major effect to the deflection and ultimate load. The deflection and ultimate load of $1.0 \mathrm{~mm}$ thick panel specimen is $16.45 \%$ and $34.45 \%$ respectively. Therefore, increased the thickness of profiled steel sheet can enhance the stiffness and strength of the lightweight composite slab systems. It also found that the infill material used in these experimental gives minor effect to deflection and ultimate load. The deflection and ultimate load of panel specimen with foamed concrete is $21.18 \%$ and $16.66 \%$ respectively. Thus, foamed concrete can be used only for non-structural purposed only such as sound proofing and fire resistance.
\end{abstract}

Keywords: Composite structure, Profiled steel sheet, Dry board, Infill material, Four-point bending test, Deflection, Stress-strain

\section{Introduction}

Nowadays, researchers and designers have more challenges with introducing low cost, time-saving (in terms of construction), and lightweight structural floor systems. These criteria are even more desirable in composite structural systems. Composite structures provide many benefits compared with simple structures. One of the most significant benefits of composite construction is its flexibility in design, offering the designer virtually infinite possibility to tailor both the geometric shape and material to optimize the structural performance [1].

Using composite systems constructed by profiled sheets and concrete is mainly utilized in buildings [2,3] especially for floors to provide a permanent formwork that also serves as bottom reinforcement $[4,5]$. That led to the introduction of a steel composite slab system called the Profiled Steel Sheeting Dry Board (PSSDB) system as shown in Fig. 1. The PSSDB system is consists of profiled steel sheet (PSS) attached to dry board (DB) using mechanical screws. It was first studies by Wrights and Evans [6] have shown that the profiled steel sheeting is capable of carrying loads up to $4 \mathrm{kN} / \mathrm{m}^{2}$ on its own (weight of wet concrete, construction tools, and labors) which surpass the serviceability limit state designed for houses, small offices, classroom and multi-story building [7-9]. 


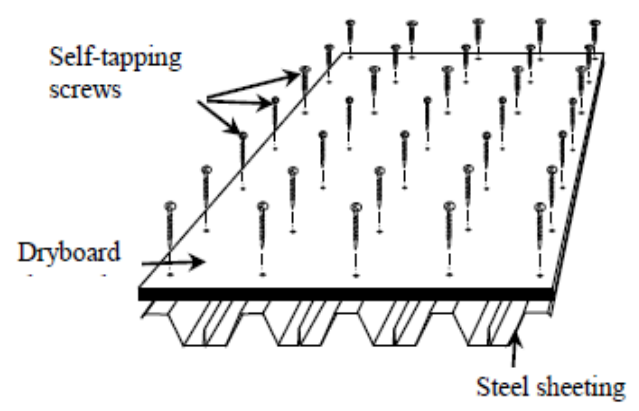

Fig. 1 - Typical PSSDB system

Studies on the behavior of the PSSDB system by using Peva 50 as a profiled steel sheet and Primaflex as a dry board has been reported in earlier publications [10-15]. Jaffar et al. [10] were investigated the connection stiffness through the push-out test and deflection in the mid-span through the bending test. The connection stiffness of PSSDB filled with geopolymer concrete is $331 \%$ higher compared to PSSDB filled with normal concrete. This contributes to a reduced $21 \%$ of deflection in the mid-span for a panel filled with geopolymer concrete. It also found that deflection in mid-span reduced $41 \%$ for PSSDB with a half-size dry board filled with geopolymer concrete compared to PSSDB with a half-size dry board filled with normal concrete [11]. This phenomenon making the panel that is filled with the geopolymer concrete $25 \%$ stronger than the normal concrete-filled panel.

Jaffar et al. [12] were investigated the mid-span deflection and rigidity of PSSDB systems with $12 \mathrm{M}$ of geopolymer concrete. The result shows that the mid-span deflection of the panel has reduced to 52\% and $107 \%$ increase in rigidity compared with those of the control (without infill). It also illustrates that the rigidity of PSSDB with a halfsize dry board filled with geopolymer concrete increases by $43 \%$ relative to that of the PSSDB with full-size filled normal concrete [13]. Steel plates can be considered an economic solution to enhance the structural behavior of the PSSDB system. Al-Shaikhli et al. [14] was investigated the stiffness and strength of the PSSDB system when enhanced with a steel plate. From the result, it was found that applying a steel plate can enhance the stiffness and strength of the PSSDB system by approximately $31 \%$ and 15\%. Applying both steel plate and infill material can enhance $13.6 \%$ instead of applying for steel plate alone. It also shows that changing the plate thickness can enhance the PSSDB stiffness. However, increasing the number of plates or changing the plate width doesn't greatly affect the performance $[15]$.

The objective of this study is to investigate the bending behavior of a lightweight composite slab system that was tested under a four-point bending test with different thicknesses of profiled steel sheet (PSS) and without or with foamed concrete. The results observed from this study are to determine the structural behavior of the lightweight composite slab system.

\section{Experimental Work}

To quantify the amount of vertical and horizontal movements of the lightweight composite slab under the static loading, an experimental test was conducted. The efficiency of lightweight composite slab system developed in this research that comprises of profiled steel sheet (Peva 50) with $0.8 \mathrm{~mm}$ and $1.0 \mathrm{~mm}$ thick and attached with the dry board (Primaflex) with the thickness of $16 \mathrm{~mm}$ on top of slab specimen using self-drilling screws connector with $200 \mathrm{~mm}$ spacing between the screws and without or with infill material. Each lightweight composite slab component has its role. Peva 50 is made from cold forming a steel strip in a rolling mill and steel is coated with zinc or zinc/aluminum alloy [16]. Primaflex is composite material flat sheet composed of the top grade cellulose fiber, Portland cement, and finely ground sand that is produced under intense pressure [17]. The self-drilling screws were used have a diameter and length of $8.0 \mathrm{~mm}$ and $32.0 \mathrm{~mm}$ respectively. The corrugations in the Peva 50 were filled with foamed concrete with a targeted density of $1600 \mathrm{~kg} / \mathrm{m}^{3}$ or compressive strength of $22 \mathrm{~N} / \mathrm{mm}^{2}$ in 28 days after mixing and casting. The characteristic of the used material can be found in Table 1.

Table 1 - Material properties

\begin{tabular}{cccc}
\hline Materials & $\begin{array}{c}\text { Thickness/ } \\
\text { Diameter } \\
(\mathbf{m m})\end{array}$ & $\begin{array}{c}\text { Modulus of } \\
\text { elasticity, E } \\
\left(\mathbf{N} / \mathbf{m m}^{\mathbf{2}}\right)\end{array}$ & $\begin{array}{c}\text { Ultimate } \\
\text { strength } \\
\left(\mathbf{N} / \mathbf{m m}^{\mathbf{2}}\right)\end{array}$ \\
\hline Profiled steel Sheet (Peva 50) & 0.8 & $275 \times 10^{3}$ & 350 \\
\cline { 2 - 4 } Dry Board (Primaflex) & 1.0 & $275 \times 10^{3}$ & 350 \\
Self-drilling screws & 16.0 & 8030 & 22 \\
\hline
\end{tabular}


A total of four full-scale lightweight composite slabs were prepared with the size of $2440 \mathrm{~mm}$ (length) $\times 1000 \mathrm{~mm}$ (width) $\times 66 \mathrm{~mm}$ (height). Two-panel specimens without foamed concrete were developed with $0.8 \mathrm{~mm}$ and $1.0 \mathrm{~mm}$ thick of profiled steel sheet (Peva 50). Other two-panel specimens were generated with the same characteristics but with foamed concrete as infill material. The test specimen can be found in Table 2.

Table 2 - Test specimens

\begin{tabular}{cccc}
\hline Group & $\begin{array}{c}\text { Specimen } \\
\text { Name }\end{array}$ & $\begin{array}{c}\text { The thickness of } \\
\text { profiled steel sheet } \\
(\mathbf{m m})\end{array}$ & $\begin{array}{c}\text { With/ Without } \\
\text { infill material }\end{array}$ \\
\hline \multirow{2}{*}{1} & $0.8 \mathrm{H}$ & 0.8 & Without infill \\
\cline { 2 - 4 } & $1.0 \mathrm{H}$ & 1.0 & Without infill \\
\hline \multirow{2}{*}{2} & $0.8 \mathrm{FC}$ & 0.8 & With infill \\
\cline { 2 - 4 } & $1.0 \mathrm{FC}$ & 1.0 & With infill \\
\hline
\end{tabular}

Simply supported condition is applied in the test to measure the horizontal movement of the specimen at the roller end. The loads will be generated via hydraulic press control and they will be symmetrically distributed on the specimen through four lines of load. The hydraulic press capacity is $1000 \mathrm{kN}$. The Linear Variable Deformation Transducers (LVDT) and strain gauges were used to measure the vertical movement and the strains at important areas. Three LVDT and strain gauges were placed to detect the vertical movements and horizontal movement of the quarter-span and midspan of the specimen. Fig. 2 shows the slab details and test setup. Monotonic static load was applied in small increments of the load until either onset of the local buckling or $80 \%$ of predicted ultimate load each of them happens sooner. The loading would be based on the deflection changes after this point. Therefore, Proper considerations have been made during preparing the specimen and performing the test to maximize the accuracy of the obtained results. Thus, the recorded results of the LVDT and the strain gauges by the data logger are reliable.

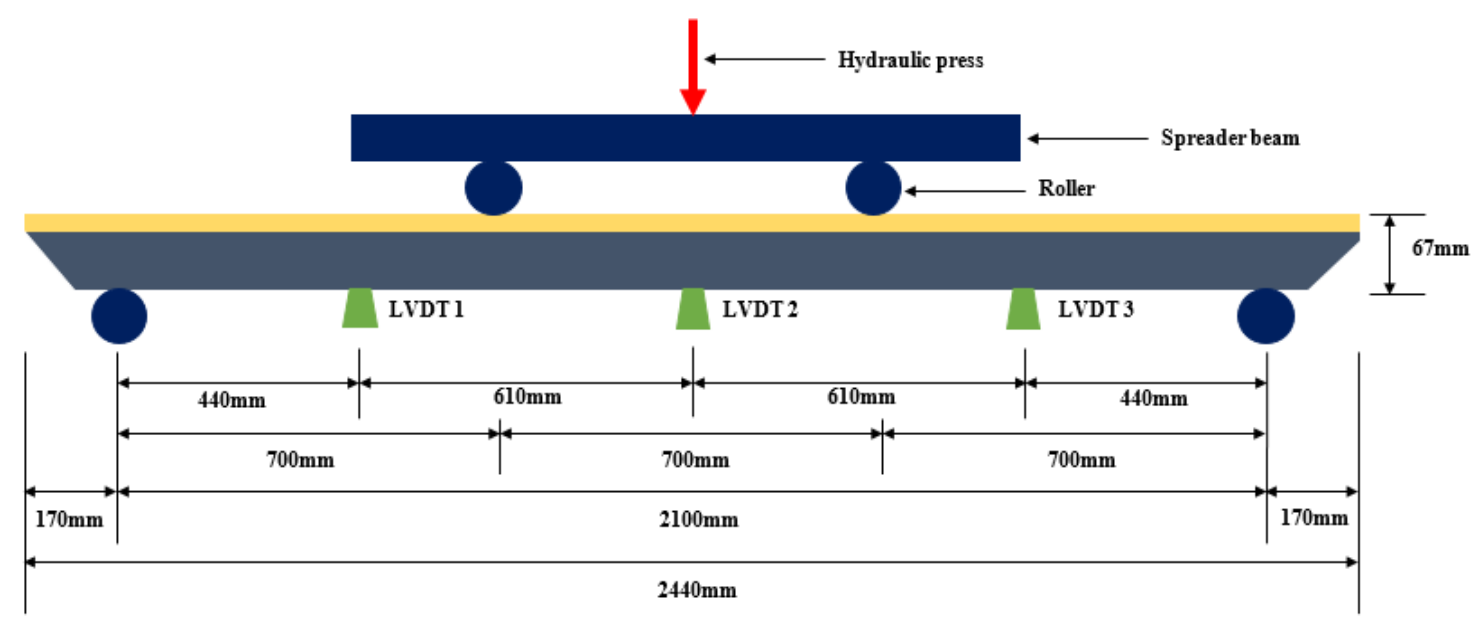

Fig. 2 - Scheme of the experimental setup

\section{Results and Discussions}

After completing the installation of the measuring devices (transducers and strain gauges) and recording equipment (data logger and laptop), and checking that all equipment were working properly, everything was ready. So the test has begun by applying an incremental load on the lightweight composite slab which has been distributed using the spreader beam and roller (see Fig. 3). 

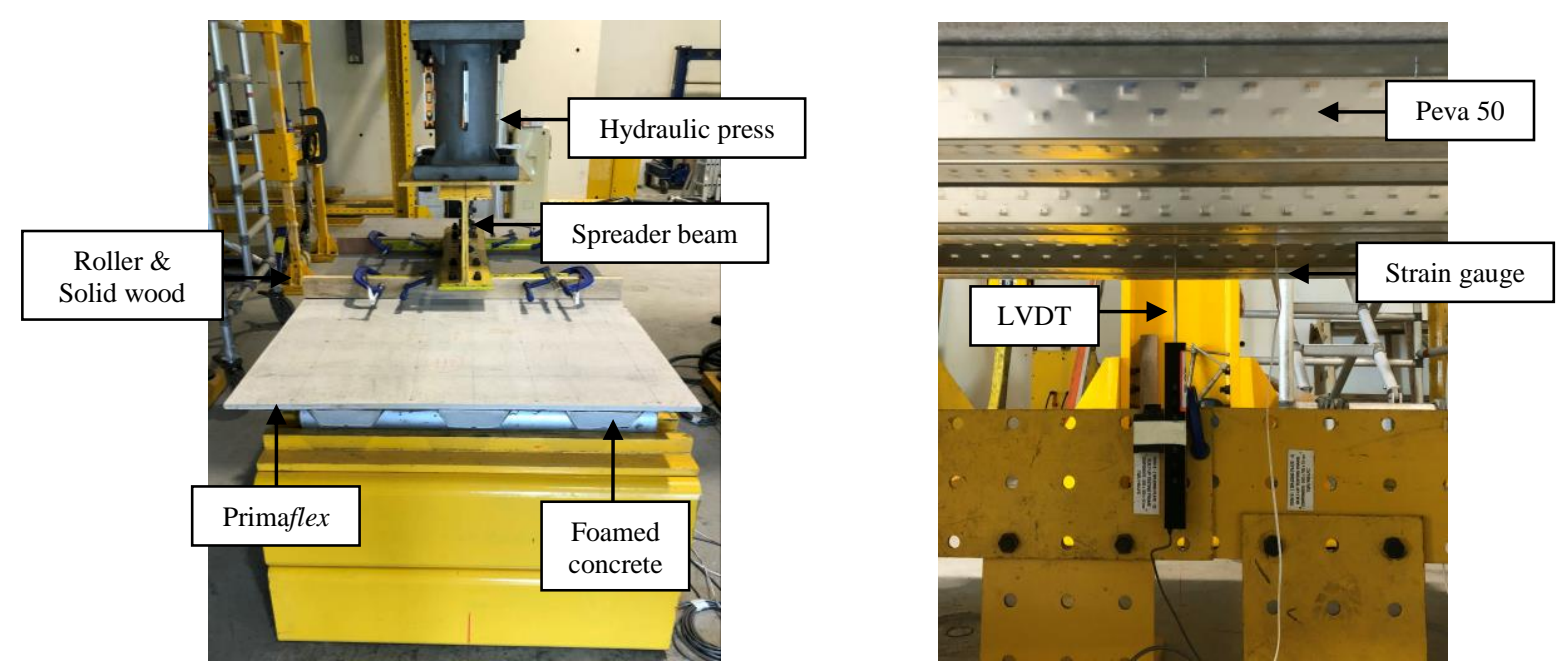

Fig. 3 - Diagonal view of lightweight composite slab

\subsection{Load-deflection Curve}

As stated above, the obtained data from the hydraulic press, LVDTs, and strain gauges were recorded using a digital data logger which in turn was displayed in a laptop device. The results of the experimental tests will be analyzed and discussed below to predict the structural behavior of the lightweight composite slab system. In the plotted graph in Fig. 4 below, the experimental results show that all tests conducted are showing similar load-deflection characteristics. The four curves show a linear at the beginning of loading and elastic response continued until just before failure. Then, the ultimate load is achieved and the panel specimen will fail. Referring to EN 1992-1-1, Cl 7.4.1, the deflections of the specimen are well within the allowable deflection limit is L/200, where L is the span distance [18]. In this case, the limiting deflection was found to be $10.5 \mathrm{~mm}$. The deflections obtained for all the panel specimens were well within the deflection limit.

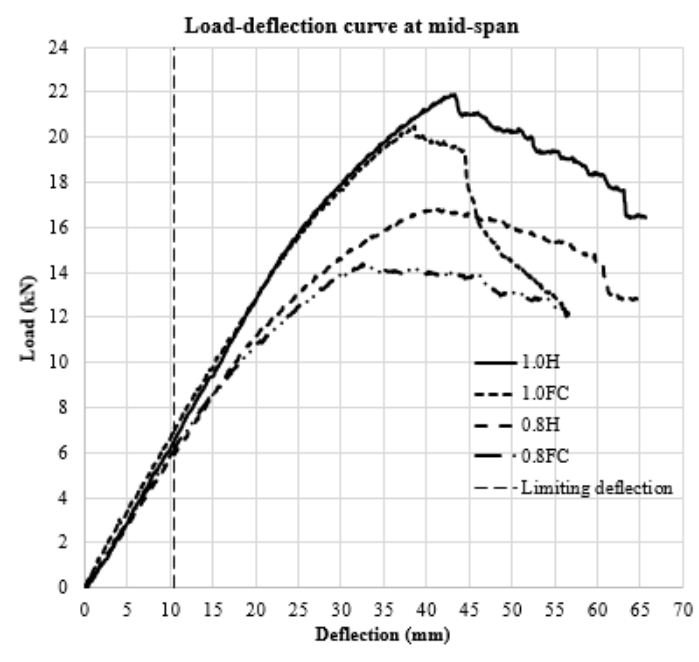

Fig. 4 - Load-deflection curve at mid-span

\subsubsection{Effect of Profiled Steel Sheet Thickness}

From the observation (see Fig. 4), the panel specimen $0.8 \mathrm{H}$ and $1.0 \mathrm{H}$ show deflection amount of $41.40 \mathrm{~mm}$ and $43.47 \mathrm{~mm}$ respectively. The ultimate load for panel specimens $0.8 \mathrm{H}$ and $1.0 \mathrm{H}$ is $16.78 \mathrm{kN}$ and $21.64 \mathrm{kN}$ correspondingly. The deflection of panel specimen $1.0 \mathrm{H}$ is higher compared to deflection of panel specimen $0.8 \mathrm{H}$ with a percentage difference of deflection is $4.88 \%$ and the ultimate load of panel specimen $1.0 \mathrm{H}$ also higher compared to ultimate load $0.8 \mathrm{H}$ with a percentage difference of ultimate load is $25.30 \%$. While the deflection of panel specimen $0.8 \mathrm{FC}$ and $1.0 \mathrm{FC}$ is $33.47 \mathrm{~mm}$ and $39.47 \mathrm{~mm}$ respectively. $14.20 \mathrm{kN}$ and $20.11 \mathrm{kN}$ of ultimate load for panel specimen $0.8 \mathrm{FC}$ and $1.0 \mathrm{FC}$ respectively. The deflection of panel specimen $1.0 \mathrm{FC}$ is higher compared to deflection panel specimen $0.8 \mathrm{FC}$ with a difference of $16.45 \%$ and the ultimate load panel specimen of 1.0FC also higher compared to the ultimate load of panel specimen $0.8 \mathrm{FC}$ with a difference of $34.45 \%$. From both results, increasing the thickness of Peva 50 from $0.8 \mathrm{~mm}$ to 
$1.0 \mathrm{~mm}$ gives a major effect on the deflection and ultimate load. Therefore, increased the thickness of profiled steel sheet can enhance the stiffness and strength of the lightweight composite slab systems.

\subsubsection{Effect of Infill Materials}

By comparing the deflection and ultimate load, the panel specimen of $1.0 \mathrm{H}$ is higher compared to $1.0 \mathrm{FC}$ with a different percentage of deflection is $9.65 \%$ and the different percentage of ultimate load is $7.33 \%$. Whereas, the deflection of panel specimen $0.8 \mathrm{H}$ is higher than the deflection of panel specimen $0.8 \mathrm{FC}$ and the ultimate load of panel specimen $0.8 \mathrm{H}$ also higher than the ultimate load panel specimen $0.8 \mathrm{FC}$ with a difference of deflection is $21.18 \%$ and the difference of ultimate load is $16.66 \%$. From both results, it is found that the infill material (foamed concrete) used in these experimental gives a minor effect on deflection and ultimate load. Thus, foamed concrete can be used only for non-structural purposes only such as soundproofing and fire resistance. It is because the lightweight composite slab with foamed concrete already sustains their heavy self-weight and cannot sustain more load from others.

\subsubsection{Symmetrical Deflection}

As mentioned before, the use of LVDT 1 and LVDT 3 is to record the symmetrical deflection at quarter-span locations. The load-deflection curves for the four cases are shown in Fig. 4 till 7. From the graphs, the deflections are seen almost identical for symmetrically positioned LVDT 1 and LVDT 3 for all samples. This situation shows the deflections recorded by the LVDTs at quarter-span locations are considered symmetrical, hence verifying the reliability of the experimental data.

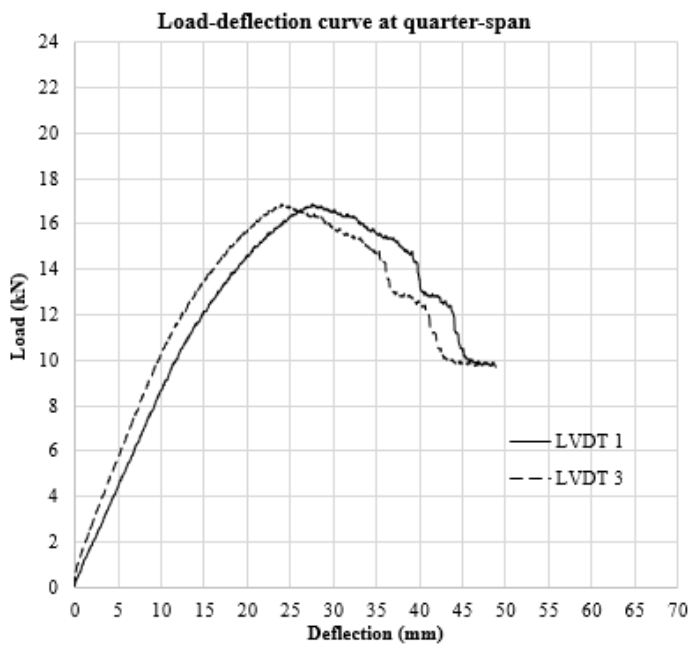

Fig. 5 - Symmetrical deflections at quarterspan for $0.8 \mathrm{H}$

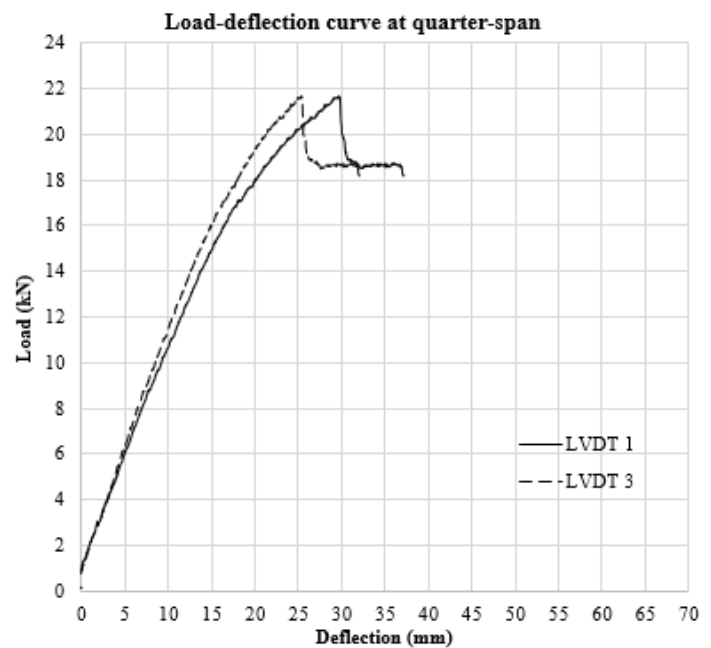

Fig. 7 - Symmetrical deflections at quarterspan for $1.0 \mathrm{H}$

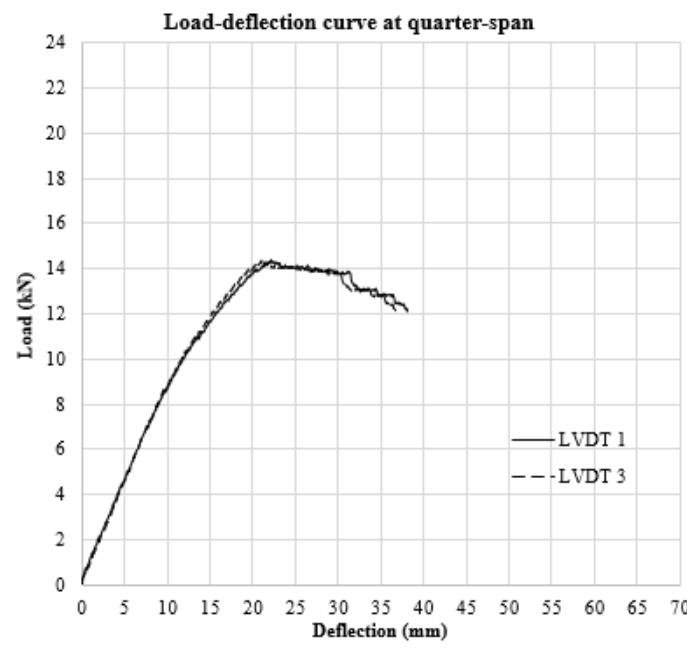

Fig. 6 - Symmetrical deflections at quarterspan for $0.8 \mathrm{FC}$

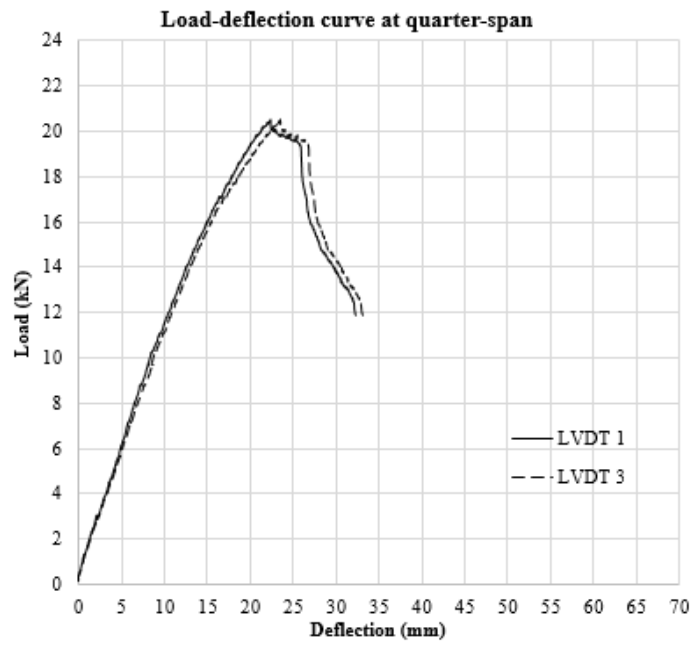

Fig. 8 - Symmetrical deflections at quarterspan for 1.0FC 


\subsection{Strain-load Curve}

Figs. 9 present the load-strain graphs which were obtained from the applied strain gauges. The strain gauge was placed at the mid-span of the panel specimen. It is clarified from the obtained results that the profiled steel sheet (Peva 50) hasn't reached the yielding point. Based on Fig. 9 (a), from the vertical strain gauges that lie on the upper flanges of the profiled steel sheet (Peva 50), it can be seen that the $0.8 \mathrm{FC}$ has reached -526 at the load $19 \mathrm{kN}$ while for $0.8 \mathrm{H}$ has reached -724 at the same load. Both values are very low comparing to the yield strain of Peva 50 which is approximately equal to -1667 . The same can be said for panel specimens of $1.0 \mathrm{H}$ where the strain values at the same load are -508 and -1497 respectively. In addition, it's worth noting that the strain gauge reading lies in the tension region which is consistent with the bending behavior demonstrated in the failure mode. The results of the strain-load curve are concordant with the failure modes where the failure occurs in the dry board (Primaflex) and the breaking of the self-drilling screws which connect the profiled steel sheet (Peva 50) and dry board (Primaflex).

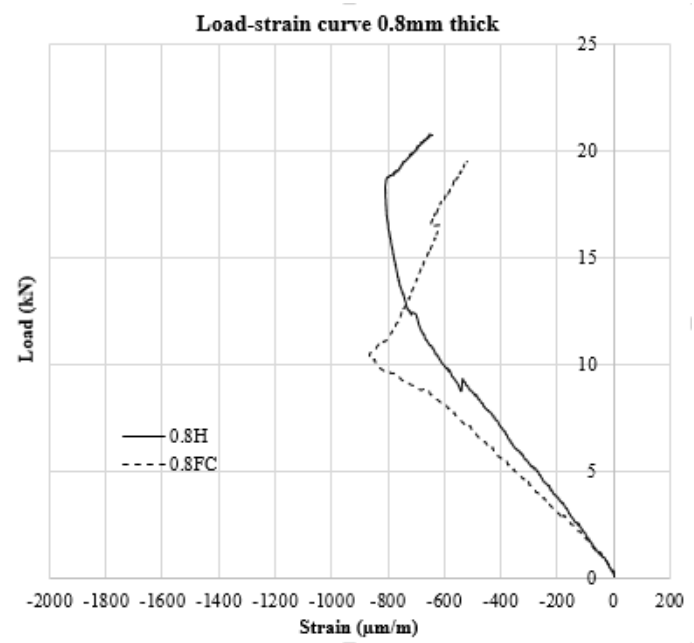

(a)

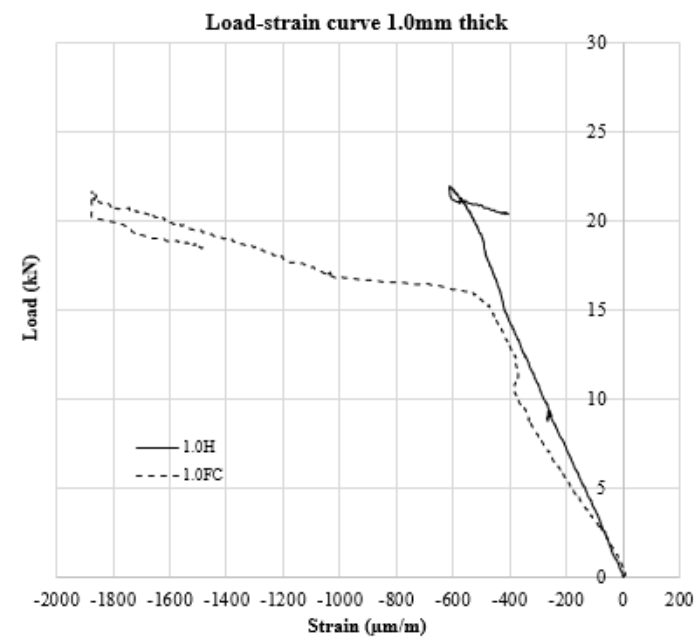

(b)

Fig. 9 - Load-strain curve (a) $0.8 \mathrm{~mm}$ thick; (b) $1.0 \mathrm{~mm}$ thick

\subsection{Failure Mode}

In the experiment conducted on a lightweight composite slab panel, failure was found to occur on the panel specimen because of local buckling, especially on the top flange of the profiled steel sheeting in the mid-span (see Fig. 10 and Fig. 11). The loading imposed on the panel specimen caused the dry board (Primaflex) to bend and the steel sheeting (Peva 50) to experience high tension, which further caused local buckling on the web of steel sheeting. The web part of the steel sheeting exhibited a remarkable deformation because of local buckling, which resulted in a nonlinear relationship in the plastic range of the load-deflection graph. The curve relationships observed in all the panel specimens tested were almost linear initially and subsequently became non-linear as a load was added continuously. The non-linear characteristics observed in all the load-deflection plots are due to the load buckling of the under compression as described in section 3.2 [19]. It can be seen that the panel specimen without foamed concrete developed local buckling only at the mid-span position. On the other hand, the panel specimen with foamed concrete demonstrated quarter span position load buckling as well that took place sometime after the mid-span local buckling. As for the panel specimen with foamed concrete, it's worth noting that the presence of embossments at the webs and bottom flanges of the profiled steel sheet (Peva 50) has managed to establish a partial interaction between Peva 50 and the foamed concrete, and it was enough to prevent a slip between the layers (see Fig. 11) 

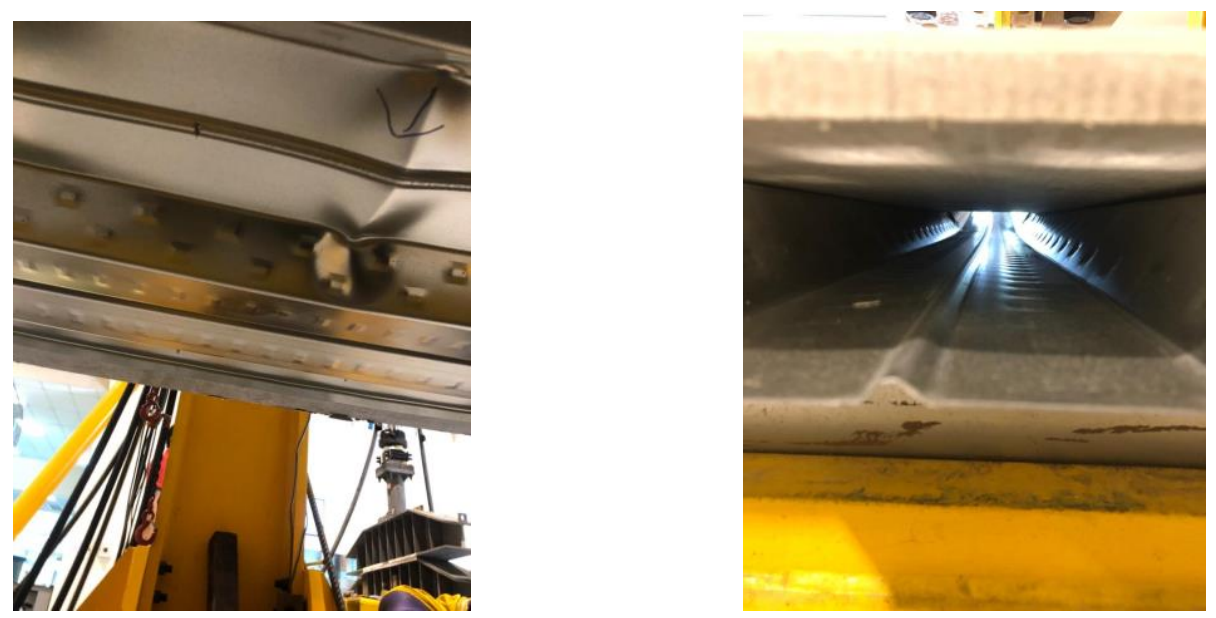

Fig. 10 - Buckling of Peva 50 without foamed concrete
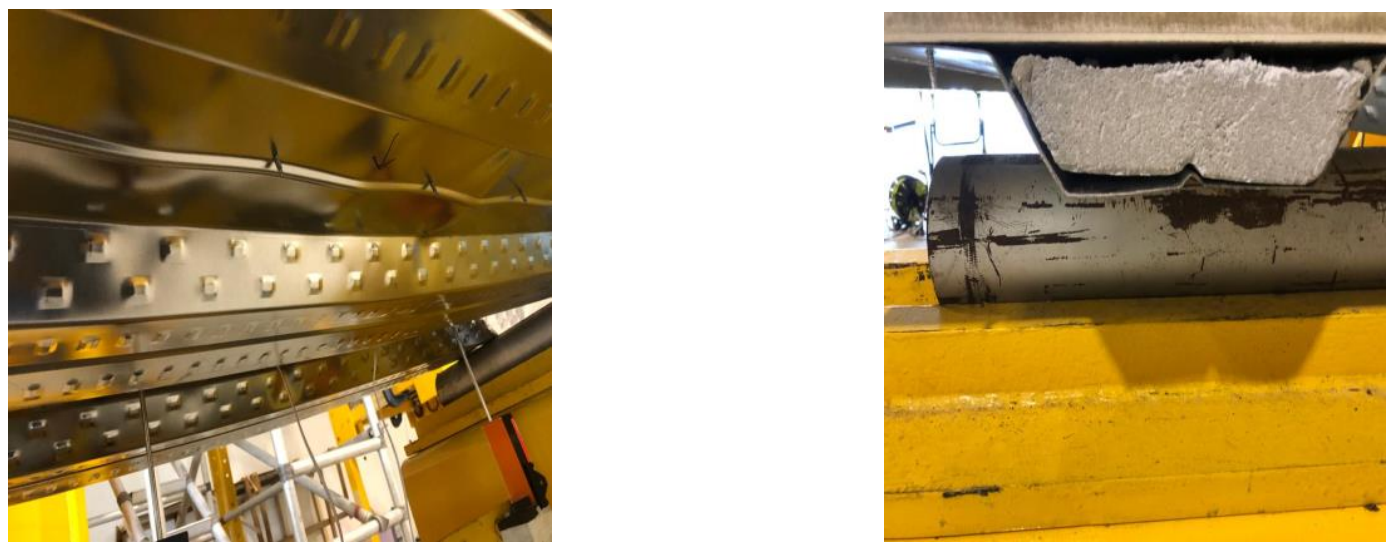

Fig. 11 - Buckling of Peva 50 and condition of foamed concrete

Failure of the panel specimen started at mid-span within the vicinity of the point of application of loading. It began with the appearance of a crack near to the mid-point of the dry board (Primaflex). With further increase in loading, the crack pattern propagated further perpendicular to the corrugation of the steel sheeting along the whole width of the panel specimen. It worth noting that the parallel edges didn't rise, and the failure of the specimen didn't occur because of the dry board (Primaflex), although some minor cracks have appeared around the mid-span as displayed in Fig. 12. As the panel specimen is loaded, the sheeting (Peva 50) will deform, allowing the screws (self-drilling screws) to lean and bite into the boarding as illustrated in Fig.13. Depending on the board types, two major modes of failure may occur here; firstly crushing of board surrounding the connectors, and secondly, screw connectors shearing off at the base. From the observation, all tests show similar and consistent behavior

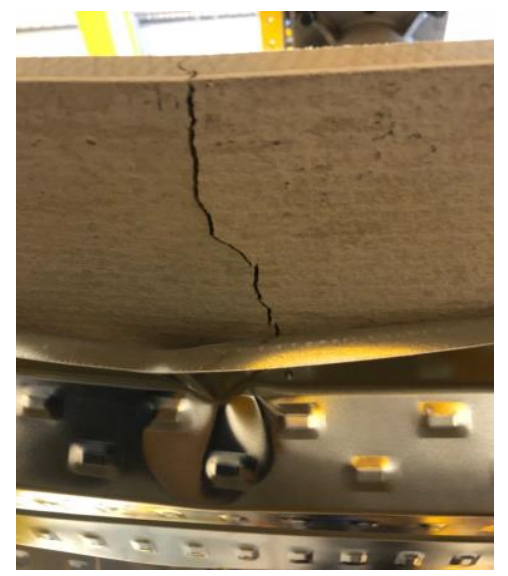

Fig. 12 - Cracking occur at mid-span 

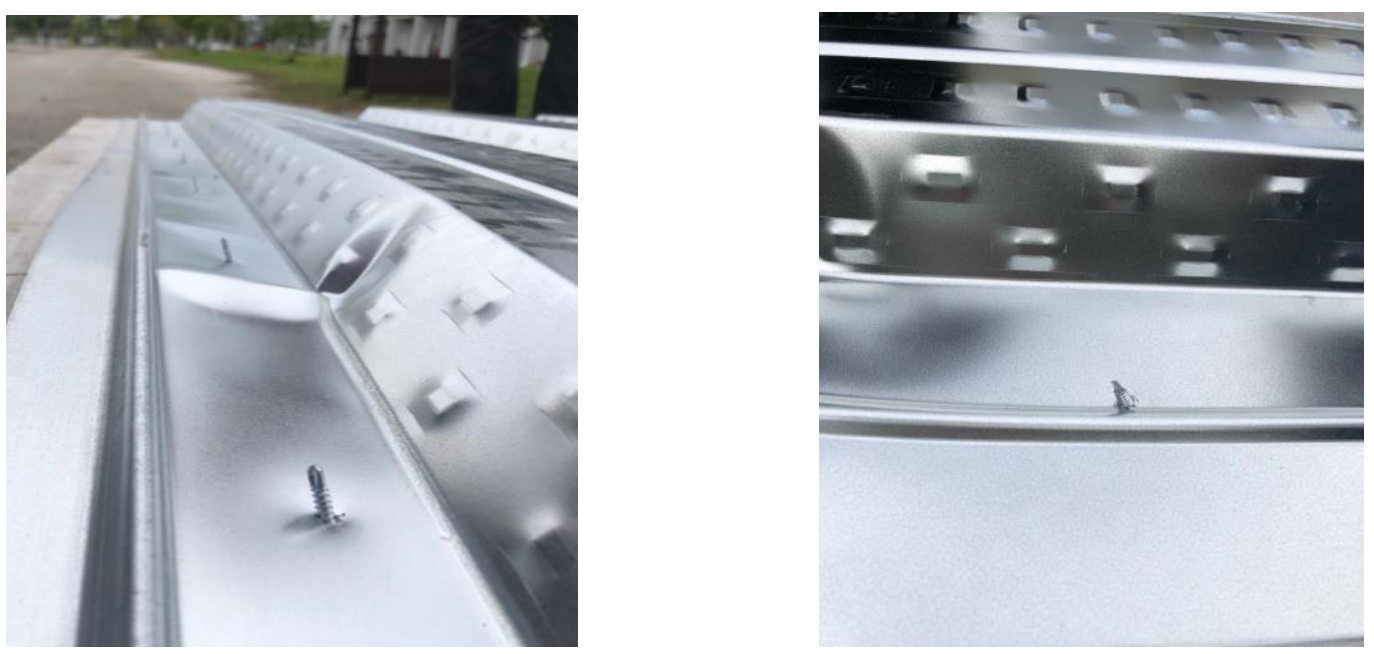

Fig. 13 - Shearing of screw connector

\section{Conclusion}

This study investigates the structural behavior of lightweight composite slab systems with the effects of different thicknesses of profiled steel sheets and without or with foamed concrete when tested subjected to bending loads. From the experiment conducted, it is found that increasing the thickness of profiles steel sheets gives a major effect on the deflection and ultimate load. Therefore, increased the thickness of profiled steel sheet can enhance the stiffness and strength of the lightweight composite slab systems. It also found that the infill material used in these experimental gives minor effect to deflection and ultimate load. Thus, infill material can be used only for non-structural purposes only such as soundproofing and fire resistance. Overall, the objectives of this study were achieved and enough to optimize the structural behavior of the lightweight composite slab system. Furthermore, it can provide an economical solution to enhance the stiffness and strength of lightweight composite slabs without affecting the system's efficiency. Further studies considering the other types of infill material must be investigated in the future.

\section{Acknowledgment}

The authors would like to thank Universiti Tun Hussein Onn Malaysia (UTHM) and the Ministry of Education Malaysia through Postgraduate Research Grant (GPPS) Vot. No. H395 for the continuous supports in terms of facilities and finances.

\section{References}

[1] Akhand, A. M. (2001). Nonlinear finite element modeling and partial plastic analysis of composite profiled steel sheeting dry board continuous floor. PhD diss., Universiti Kebangsaan Malaysia

[2] Mistakidis, E. S., \& Dimitriadis, K. G. (2008). Bending resistance of composite slabs made with thin-walled steel sheeting with indentations or embossments. Thin-walled structures, 46(2), 192-206

[3] Abdullah, R., \& Easterling, W. S. (2009). New evaluation and modeling procedure for horizontal shear bond in composite slabs. Journal of constructional steel research, 65(4), 891-899

[4] Jeong, Y. J. (2008). Simplified model to predict partial-interactive structural performance of steel-concrete composite slabs. Journal of Constructional Steel Research, 64(2), 238-246

[5] Ferrer, M., Marimon, F., \& Casafont, M. (2018). An experimental investigation of a new perfect bond technology for composite slabs. Construction and Building Materials, 166, 618-633

[6] Wright, H. D., \& Evans, H. R. (1986). Profiled steel sheeting for the replacement of timber flooring in building renovation. SERC Grant GR/D/76875. United Kingdom

[7] Wright, H. D., Evans, H. R., \& Harding, P. W. (1987). The use of profiled steel sheeting in floor construction. Journal of Constructional Steel Research, 7(4), 279-295

[8] Badaruzzaman, W. W., Zain, M. F. M., Akhand, A. M., \& Ahmed, E. (2003a). Dry boards as load bearing element in the profiled steel sheet dry board floor panel system-structural performance and applications. Construction and Building Materials, 17(4), 289-297

[9] Awang, H., \& Badaruzzaman, W. H. W. (2011). Development of profiled steel sheeting dry board roof panel system in school classroom modules. Journal of Civil Engineering and Construction Technology, 2(4), 72-81 
[10] Jaffar, M. I., Wan Badaruzzaman, W. H., Al Bakri Abdullah, M. M., \& Abd Razak, R. (2015b). Comparative study floor flexural behavior of profiled steel sheeting dry board between normal concrete and geopolymer concrete in-filled. In Applied Mechanics and Materials (Vol. 754, pp. 364-368). Trans Tech Publications Ltd

[11] Jaffar, M. I., Wan Badaruzzaman, W. H., Al Bakri Abdullah, M. M., Kamarulzaman, K., \& Seraji, M. (2015a). Effect of geopolymer concrete infill on profiled steel sheeting half dry board (PSSHDB) floor system subjected to bending moment. In Applied Mechanics and Materials, 754, 354-358. Trans Tech Publications

[12] Jaffar, M. I., Badaruzzaman, W. H. W., Abdullah, M. A. B., Baharom, S., Moga, L. G., \& Sandu, A. V. (2015c). Relationship between panel stiffness and mid-span deflection in Profiled steel sheeting dry board with geopolymer concrete infill. Materiale Plastice, 52(2)

[13] Jaffar, M. I., Badaruzzaman, W. H. W., \& Baharom, S. (2016). Experimental tests on bending behavior of profiled steel sheeting dry board composite floor with geopolymer concrete infill. Latin American Journal of Solids and Structures, 13(2), 272-295

[14] Al-Shaikhli, M. S., Badaruzzaman, W. H. W., Baharom, S., \& Al-Zand, A. W. (2017). The two-way flexural performance of the PSSDB floor system with infill material. Journal of Constructional Steel Research, 138, 79-92

[15] Samir, M., Badaruzzaman, W. W., Baharom, S., \& Hilo, S. J. (2015). The flexural performance of the profiled steel sheeting dry board (PSSDB) system as a two-way floor panel, strengthened with steel plates. In Proceedings of Sixteenth TheIIER International Conference, Kuala Lumpur, Malaysia (pp. 133-135)

[16] Ajiya Roofing Industries Sdn. Bhd. (2012). Ajiya Peva 50 composite floor decking structural product [Brochure]. Malaysia, ON: Author

[17] Hume Cemboard Industries Sdn. Bhd. (2008). PRIMA flex [Brochure]. Malaysia, ON: Author

[18] En, B. S. (1992). 1-1: 2004 Eurocode 2: Design of concrete structures. General rules and rules for buildings, 1992-3

[19] Jaffar, M. I., Badaruzzaman, W. H. W., \& Baharom, S. (2016). Experimental tests on bending behavior of profiled steel sheeting dry board composite floor with geopolymer concrete infill. Latin American Journal of Solids and Structures, 13(2), 272-295 